\title{
Casas y cosas en la Galicia occidental en el siglo XVIII
}

\author{
Ofelia Rey Castelao \\ Universidad de Santiago de Compostela \\ ofelia.rey@usc.es
}

Fecha de recepción: 25/05/2015

Fecha de aceptación: 04/06/2015

\section{RESUMEN}

Este artículo se desarrolla en tres niveles: los problemas de la documentación para estudiar las casas rurales y urbanas en el siglo XVIII; el tamaño y las características de las casas rurales de la Galicia occidental; las casas de las ciudades -Santiago de Compostela y A Coruña-. Se hace una comparación entre las viviendas de esos dos espacios; las de la hidalguía y los campesinos; y las de los ricos comerciantes que se convirtieron en un sector influyente en la segunda mitad del siglo. Además, se plantean las vías mediante las cuales se acumulaban bienes en las casas.

Palabras clave: Casas, palacios, dotes, inventarios, Galicia.

\section{Houses and Things in the Western Galicia, $18^{\text {th }}$ Century}

\begin{abstract}
This article develops in three levels: a) the problems of the documentation to study the rural and urban houses in the 18th century; b) the size and the characteristics of the rural houses of the western Galicia; c) the houses of the cities -Santiago de Compostela and Coruna-. A comparison is done between the housings of both areas; those of the nobility and the peasants; and those of the rich merchants who turned into an influential sector during the second half of the century. In addition, the routes by means of which goods were accumulated in the houses.
\end{abstract}

Key words: Houses, palaces, dowries, inventories, Galicia. 
En estas páginas presentamos una síntesis sobre el medio material de la existencia cotidiana en la Galicia occidental, intentando contrastar el ámbito rural -sin duda el mejor conocido- con el urbano, minoritario en Galicia, pero del que salían, al fin, los modelos y hábitos de vida; nos interesa también exponer las características físicas de las viviendas y las posibles vías de suministro de los bienes que constituían su dotación interior. Ese es nuestro objetivo principal, pero además nos guía el de llamar la atención sobre las limitaciones de varias de las fuentes más utilizadas en los estudios sobre vida cotidiana, de las que puede parecer que todo está dicho; nos valdremos para esto de la experiencia acumulada por la historiografía gallega desde comienzos de los años setenta del siglo XX, cuando la influencia de la historia rural y de la historia social francesas se tradujo en una investigación sobre fuentes notariales y fiscales regida por las advertencias metodológicas de autores pioneros en su empleo como Pierre Goubert ${ }^{1}$. Esa experiencia dio lugar a numerosas publicaciones referidas a zonas rurales, si bien es verdad que atendían menos a las cosas de la casa que al instrumental y a la dotación laboral -agrícola fundamentalmente- y a los niveles económicos deducibles de la disponibilidad de esos medios; también se publicaron desde comienzos de los años ochenta algunos artículos sobre la ciudad de Santiago de Compostela, que observaban las casas y las cosas inspirados también en la historia social francesa y, por lo tanto, en la diferenciación por niveles de riqueza, además de interesarse por la presencia de libros en las casas. Debe tenerse en cuenta que esas perspectivas se correspondían con las corrientes historiográficas vigentes por entonces, en las que la dimensión cotidiana era solo complementaria ${ }^{2}$; posteriormente, al hilo de los avances a favor de esta otra faceta, se hicieron relecturas como la de Pegerto Saavedra en su libro de 1994 sobre la vida cotidiana en la Galicia del Antiguo Régimen, que sintetiza los resultados de la bibliografía gallega, añadiendo referencias documentales narrativas que dan color y calor humano a aquellos resultados ${ }^{3}$; de lo que después se hizo, conviene destacar la importancia de los estudios sobre la familia, no en vano la casa es su escenario vital, y sobre las mujeres, por cuanto eran ellas las responsables de la gestión de la vivienda, lo que ha contribuido a esta faceta humanizadora.

\section{LAS FUENTES Y LOS MÉTODOS}

Galicia es un territorio problemático para estudiar lo que no es economía por la dificultad de encontrar documentación escrita sobre aspectos como el que nos ocupa. El enorme analfabetismo nos priva de contar con testimonios escritos familiares, en es-

1 GOUBERT, P.: "Intérêt et utilisation historiques des papiers de succession: inventaires après décès, partages, comptes de tutelle", Revue d'Histoire moderne et contemporaine (1954), pp. 22-34.

2 El propio Goubert, cuya influencia es evidente en el grupo compostelano, avanzó esa línea en La Vie quotidienne des paysans françaises au XVIIe siècle, París, Hachette, 1982. Consagrada en BAULANT, M. y otros: Inventaires après-décès et ventes de meubles: apports à une histoire de la vie économique et quotidienne (XIVe-XIXe siècle), París, Academia, 1988.

3 SAAVEDRA FERNANDEZ, P.: La vida cotidiana en la Galicia del Antiguo Régimen, Barcelona, Crítica, 1994. 
pecial sobre el campesinado, sector mayoritario de la sociedad gallega, y la debilidad de la red urbana colabora en ese déficit; por otra parte, ni los observadores autóctonos ni los visitantes fueron expresivos al describir los modos de vida de los gallegos, y los escasos textos narrativos que se han referido al modo de vida del campesinado gallego en la Edad Moderna se concentran en el siglo XVIII y son escuetos en sus contenidos ${ }^{4}$. Esto contrasta con la propensión de los gallegos a acudir al notario para escriturarlo casi todo, lo que tiene su base en el predominio del reparto desigual de la herencia entre los hijos e hijas, y en la intensa emigración, lo que recomendaba poner por escrito las decisiones al respecto para evitar conflictos tanto entre herederos presentes como sobre todo con los posibles retornados. Así pues, la tipología de las escrituras era la misma que en cualquier otro territorio, pero sus causas profundas tienen esas variantes y la evolución de los diferentes tipos no fue la misma, lo que consideramos crucial para explicar la desaparición paulatina de algunos.

Más homologables a lo común en la Corona de Castilla son las fuentes de carácter fiscal. El Catastro del marqués de La Ensenada no solo ha facilitado el acceso a la clasificación de los niveles socio-económicos de las familias y grupos rurales y urbanos y, por lo tanto, calibrar sus posibilidades de consumo, sino también, en donde fue posible, conocer la tipología y caracteres de las viviendas. Así pues, con todas las precauciones ante su naturaleza fiscal, es esencial para el estudio de la vivienda rural, ya sea rica o pobre. Como sabemos, en los libros de las declaraciones reales, la casa, con su valoración fiscal -en términos de alquiler-y sus dimensiones y alturas, así como la enumeración de alpendres y edificaciones secundarias, son datos que se ofrecen siempre y que pueden ponerse en relación con el tamaño de la familia declarante, por lo que su estudio es de una enorme utilidad a pesar de no ofrecer una descripción mínima de las casas -techumbres, vanos, paredes-y de los materiales de construcción. Su empleo para establecer la tipología de las viviendas rurales se hizo por primera vez en 1973 por parte de Hilario Rodríguez Ferreiro para una zona del interior occidental, la tierra de Trasdeza ${ }^{5}$. Su trabajo ofrecía un cálculo relativamente sencillo que ponía en relación la valoración fiscal con la configuración y el tamaño de las viviendas expresado en metros cuadrados, y con el número de sus ocupantes, como veremos; más adelante, Hortensio Sobrado Correa utilizó la misma fuente para estudiar la vivienda de la antigua provincia de Lugo ${ }^{6}$.

Así pues, las fuentes empleadas para estudiar el marco de la vida cotidiana en la Galicia moderna son las escrituras notariales habituales -especialmente, inventarios post-mortem y dotes matrimoniales- y la documentación fiscal, cruzándolas en la medida de lo posible, y tratando de reunir retazos de difícil integración, dado que los cambios en el tiempo pueden llegar a distorsionar lo que se observa. Las fuentes fiscales ayudarían a comprender el significado y contenido de las escrituras notariales

4 GARRIDO, G. A.: "A Literatura de viaxes como fonte histórica, viaxeiros estranxeiros por Galicia, séculos XVIII a XX”, en DE JUANA, J. y otros (dirs.): VII Xornadas de Historia de Galicia, Ourense, Deputación, 1993, pp. 209-223.

5 RODRIGUEZ FERREIRO, H.: La Tierra de Trasdeza. Una economía rural antigua, Santiago, Universidad, 1973, pp. 153 a 158.

6 SOBRADO CORREA, H.: Las Tierras de Lugo en la Edad Moderna: economía campesina, familia y herencia, 1550-1860, A Coruña, Fundación Barrié, 2001. 
y estas a su vez a cubrir las deficiencias de las fiscales. Sin ir más lejos, las declaraciones particulares del Catastro se realizaron en unos años, 1752/53, en los que los inventarios y las dotes son cada vez menos frecuentes y menos expresivos; al contrario, estos son abundantes y mucho más significativos en el siglo XVII, para el que carecemos de una fuente fiscal similar: es decir, para el siglo XVII sabemos más del interior que del exterior de las casas, y en el XVIII a la inversa, ya que los inventarios apenas hacen referencias a los edificios ni a sus habitantes.

Pero con esas limitaciones tenemos que trabajar y eso es lo que se hizo en la universidad de Santiago desde antes de las I Jornadas de Metodología Aplicada de 1973, en las que Antonio Eiras Roel, con Ramón Villares, presentó un primer trabajo sobre inventarios post-mortem, de gran interés porque señala tanto sus ventajas como, sobre todo, sus problemas. En esa aportación se utilizaban 125 escrituras de la Tierra de Santiago de 1675 a 1700 para recomponer la despensa y los útiles de trabajo de las casas rurales. El profesor Eiras definía el inventario como un -recuento completo, realizado ante fedatario público, de los bienes muebles, enseres, aperos, alimentos cosechados o producidos y ganados de una familia campesina, realizado en el momento de fallecer el cabeza de familia-, lo que a priori lo convertía en una fuente ideal ${ }^{7}$. Sin embargo, en una nota advertía de su escasez ya que para reunir aquella muestra se habían examinado las escrituras de 531 protocolos. Esta advertencia iba acompañada de otra no menos importante: en determinadas jurisdicciones o cotos señoriales se hacía de modo sistemático el recuento notarial de los bienes de los jefes de familia que morían -era el caso del coto de Rivadulla, próximo a Compostela- lo que generaba una concentración territorial, mientras que donde no había esa costumbre o ese mandato -se ignora la verdadera razón-, eran infrecuentes.

Es decir, los inventarios son una escritura cara y selectiva que solo se hace en condiciones de estrés familiar, esto es, cuando hay menores, ausentes o posibles conflictos por el reparto de la herencia, y para prever todo esto, en algunos casos concretos se hacía como acto preventivo por parte de los señores. Pero quizá la advertencia más importante es que a pesar de su interés, los inventarios no pueden emplearse solos porque solo reflejan bienes muebles y no la tierra y otras pertenencias y porque no suelen decir el número de componentes de la familia -y cuando lo dicen, esta es más amplia que la media, porque no solía hacerse inventario donde había un único heredero o heredera, o los bienes partibles valían menos que el coste de la escritura-. Así pues, solo se obtiene una imagen parcial de las casas rurales, y algo distorsionada de sus contenidos, ya que se constatan variaciones dependiendo de los meses del año a los que correspondieran, lo que afecta de un modo claro a los bienes perecederos o a las existencias de fibras textiles ${ }^{8}$. Conscientes de estos problemas, los historiadores

7 EIRAS ROEL, A. y VILLARES PAZ, R.: "Información serial de inventarios post-mortem", Actas de las I Jornadas de Metodología Aplicada de las Ciencias Históricas, III, Santiago, Universidad, 1975, pp. 183-202.

8 VILLARES, R.: "El consumo alimenticio en el área rural compostelana a fines del s. XVII", Compostellanum (1972), p. 65. SOBRADO CORREA, H.: "Los inventarios post-mortem como fuente privilegiada para el estudio de la historia de la cultura material en la Edad Moderna", Hispania, 63, 215 (2003), pp. 825-861; "Aproximación al consumo alimentario en el área rural gallega: el interior lucense, ss. XVII-XIX”, Obradoiro de Historia Moderna (1994), p. 87. 
ruralistas posteriores los emplearon en combinación con otras fuentes, tal fue el caso de José Manuel Pérez García en 1975 para su denso análisis sobre la península de Salnés ${ }^{9}$, pero fue el mismo autor quien comprobó que desde 1670 los inventarios se hacían cada vez menos frecuentes en la Galicia occidental ${ }^{10}$, de ahí que el muestreo del profesor Eiras consiguiera tan pocos resultados. Años más tarde se comprobaría que en la Galicia oriental, donde los inventarios eran también poco frecuentes, el descenso se retrasó los años sesenta del siglo XVIII, lo que demostraba los efectos de la coyuntura agraria ${ }^{11}$. Un cálculo un poco diferente pero que lleva a parecidas conclusiones es el realizado por I. Dubert para la Tierra de Santiago, en el que se confirma el mismo descenso al vaciar todas las escrituras referidas a la transmisión patrimonial intrafamiliar, entre las que los inventarios pasan del 5.5\% en 1706/7 al $4,3 \%$ en $1750 / 54$ y al $1,6 \%$ en $1790^{12}$.

En cuanto a los inventarios urbanos, el primer estudio realizado en Galicia fue el de Baudilio Barreiro Mallón sobre las clases urbanas compostelanas en el siglo XVIII, publicado en $1981^{13}$, en el que también se llama la atención sobre la rareza de esa fuente y de su sesgo a favor de los grupos acomodados, pero en el que tras una severa purga crítica, se da una perspectiva completa de las casas urbanas. Obviamente, el empleo de los inventarios se ha demostrado más útil, al menos para aquellas familias que tenían una sola vivienda, ya que en las clases pudientes se genera el problema de que sería preciso controlar los inventarios de las segundas y terceras residencias. Así por ejemplo, el hallazgo del inventario de los bienes del marqués de Santa Cruz de Rivadulla en su palacio rural del valle del Ulla ofreció en 1978 una imagen parcial de su espacio vital, que se pudo completar cuando se localizó en 1993 el de su palacio compostelano, tan lujoso o más que el rural ${ }^{14}$. Ambos problemas, esto es, la escasez de inventarios y la doble residencia, fueron medidos poco después cruzando los datos socio-económicos del Catastro de La Ensenada de Santiago con las escrituras nota-

9 PEREZ GARCIA, J.M.: Un modelo de sociedad rural de Antiguo Régimen en la Galicia costera: la Península del Salnés, Santiago, Universidad, 1979. Luego se harían otros muchos: SAAVEDRA FERNANDEZ, P.: "Evolución de una agricultura de autoconsumo a través de los inventarios post mortem: la Galicia cantábrica: 1600-1800”, en EIRAS ROEL, A. (ed.), La documentación Notarial y la Historia, I, Santiago, Universidad, 1984, pp. 317-334. ERIAS MARTINEZ, A.: “Algunos aspectos de la economía agraria, a través de los inventarios "post mortem", en la comarca compostelana (1750-59)", Boletín de la Real Academia Gallega, 358 (1986) pp. 92-106. QUIROGA BARRO, G.: Evolución dunha estructura agraria na Galicia interior: a terra de Viana do Bolo, 1600-1820, Ourense, Museo Arqueolóxico, 1992.

10 PEREZ GARCÍA, J.M.: "Los inventarios post-mortem como indicadores de la riqueza ganadera: Galicia occidental (1600-1669)", en EIRAS ROEL, op. cit. (nota 9), pp. 297-315.

11 En la tierra de Celanova entre 1630 y 1850 se localizaron solo 188 en 66 escribanos de treinta parroquias, suficientes para constatar que el $80 \%$ de los bienes eran muy básicos; RODRIGUEZ FERNANDEZ, D.: "Desigualdades sociales y criterios de consumo diferenciados: cultura material y nivel de vida en la Galicia interior, Celanova (1630-1850)", Cuadernos feijonianos de Historia moderna, I (1999), pp. 193-231.

12 DUBERT, I.: Historia de la Familia en Galicia durante la época moderna, 1550-1830, Sada, Ed. do Castro, 1992, p. 32.

13 BARREIRO MALLON, B.: "Las clases urbanas compostelanas de Santiago en el siglo XVIII: definición de un estilo de vida y pensamiento", en EIRAS ROEL, A. (coord.), La Historia social de Galicia, Santiago, Universidad, 1981, p. 449.

14 El rural fue localizado en 1978 (REY CASTELAO, O.: Historia rural en la comarca de la Ulla, siglos XVII y XVIII, Santiago, Universidad, 1981, pp. 155-157) y el urbano años después (FERNANDEZ GASALLA, L.: "La Biblioteca de D. Andrés de Mondragón, I Marqués de Santa Cruz de Rivadulla, mecenas y político gallego del siglo XVII (1645-1709)", Cuadernos de estudios gallegos, 42, 107 (1995), pp. $449-564$. 
riales registradas en la ciudad en el mismo año de su realización 1752: Eiras Roel reveló que en las 365 escrituras de las élites solo aparecieron dos inventarios, a pesar de que ese grupo compuesto por 155 vecinos, el 3,4\% del vecindario, le correspondía el $31,5 \%$ de las escrituras; en el mismo estudio se constataba que al menos doce de esas familias tenían residencias rurales. En el otro extremo social, E. Martínez Rodríguez comprobó que los 1.798 artesanos -el 39,9\% del vecindario- solo constaban en 326 escrituras -el 24,5\% de las registradas- en las que no aparece ningún inventario, aunque sí tres partijas ${ }^{15}$.

En cuanto a las dotes matrimoniales, son sin duda otra fuente esencial pero no sin problemas. Utilizadas por primera vez en Galicia en las investigaciones de historia rural ya citadas, los estudios más sistemáticos de Concepción Burgo López sobre la dote como indicador de las diferencias sociales y los de Serrana Rial García sobre la dote como patrimonio personal de las mujeres ${ }^{16}$, pusieron a la luz sus ventajas y sus problemas, en especial el de su representatividad. Lo cierto es que en la Tierra de Santiago, zona de reparto desigual de la herencia, a mediados del XVIII, afectaban solo al diez por ciento de los matrimonios contraídos en las parroquias rurales y al 6.3\% en Compostela. En esta ciudad en 1752 solo se recontaron trece dotes entre las 365 escrituras de las elites y 27 entre las 326 de los artesanos, siendo además poco explícitas en el contenido mueble, ya que se primaba la entrega de dinero, o al menos así se hacía constar ${ }^{17}$. Entre los problemas señalados en diferentes trabajos se subraya además que las dotes no se daban solo a las novias, ya que el 7\% se daban a hijos y el $30 \%$ eran dotes dobles - una parte incluye mejoras a los hijos dotados- y el $16.5 \%$ se referían a matrimonios cruzados; es importante señalar que un $61 \%$ eran en realidad promesas o seguros de legítima, esto es, compromisos suscritos por los padres de que no tocarían los bienes que correspondiesen a los novias o novios como legítima en la herencia, sin aportar bienes significativos en el momento de la boda. Dicho de otro modo, en el modelo matrimonial de la Galicia occidental, las mujeres se casaban a una edad elevada -28/29 años-, con frecuencia cuando ya habían muerto el padre o la madre y habían recibido su legítima, o sin esperar a esto, recibían algunos bienes que no se escrituraban, o si se iba al notario era para asegurar una futura legítima; muchas novias habrían reunido algún dinero o cosas gracias a su trabajo, o recibido alguna donación o legado de parientes sin hijos, de modo que la dote ante notario, que costaba dinero, era minoritaria y, además, como los inventarios, disminuyen en frecuencia ${ }^{18}$. En efecto, corroborando lo que se intuía en trabajos anteriores ${ }^{19}, \mathrm{C}$. Burgo constató que entre 1.531 escrituras registradas en 1645 por los escribanos de

15 EIRAS ROEL, A.: "Las elites urbanas de una ciudad tradicional: Santiago de Compostela a mediados del siglo XVIII", en EIRAS ROEL, op. cit. (nota 9) I, p. 118. MARTINEZ RODRIGUEZ, E.: "El artesanado urbano de una ciudad tradicional. Santiago de Compostela a mediados del siglo XVIII", Ibidem, pp. 141-164.

16 BURGO LOPEZ, C.: "Niveles sociales y relaciones matrimoniales en Santiago y su comarca (16401750) a través de las escrituras de dote", en EIRAS ROEL, op. cit. (nota 9) I, p. 177. RIAL GARCIA, S.: Mujer y actividad económica en la Galicia moderna, Universidad de Santiago, tesis inédita, 2002.

17 EIRAS ROEL, op. cit. (nota 15), p. 118.

18 FERNANDEZ CORTIZO, C.J.: "Matrimonio y régimen dotal en la Galicia de transición al interior en el siglo XVIII", en LOBO DE ARAUJO, M.M. y ESTEVES, A. (coords.), Tomar estado: dotes e casamentos (séculos XVI-XIX), Braga, CITCEM, 2010, pp 33-55.

19 REY CASTELAO, op. cit. (nota 14), p. 89. 
la Tierra de Santiago, solo un 5\% eran dotes, pero en 1752 solo eran el $2 \%$ de un total de 2.469, una reducción porcentual que obliga a reinterpretar este tipo de documentos y a revisar su utilidad y significado a la hora de emplearlos para ver cómo se constituían las casas de los nuevos casados. Paralelamente, entre las escrituras referidas a la transmisión patrimonial, I. Dubert probó idéntico descenso de la proporción de dotes -del 19,6\% en 1706/7 al 9,5\% a mediados del XVIII y a un 3,9\% a fines de siglo-, en paralelo con el incremento de los seguros de legítima -del 2,7\% al 4,5\% y al $12,9 \%$ en los mismos años- y la creciente importancia de las donaciones -entre el 25,7\% y el $28,8 \%$. El estudio de la dote, a día de hoy, no puede estudiarse sin tener en cuenta el sistema hereditario.

\section{VIVIR EN EL CAMPO}

Las dificultades documentales señaladas no han impedido que se haya avanzado notablemente en la definición de los modos de vida de la Galicia occidental del siglo XVIII, más que del XVII, por faltar una referencia global como el Catastro, y mucho más que del XVI, por una general mayor carencia de fuentes. Por otra parte, una vez superado el enfoque económico de los años setenta y ochenta, la observación social basada en la medición de la dotación material de las viviendas y de los grados de bienestar -y su evolución en el tiempo- permitió obtener una perspectiva diferenciada de los espacios rurales y de los urbanos, así como de los grupos sociales en sus grandes divisiones, lo que a su vez facilita una aproximación que exponemos en las páginas siguientes.

Partimos para ese objetivo de una constatación esencial: en las dos provincias gallegas que nos interesan, Santiago y A Coruña, había una población eminentemente rural. A mediados del XVIII, según los datos catastrales, y en 1787, según los del censo de Floridablanca, solo el $12 \%$ de la población era urbana en la primera, concentrándose en Compostela y en las villas -Pontevedra, Noia, Muros, Padrón, etc.-, y el $19,4 \%$ en la de Coruña, un porcentaje elevado por el simple efecto estadístico del peso de la capital en una provincia de muy pequeño tamaño; en todo caso, ambas provincias se situaban por encima de la media de Galicia.

La segunda constatación esencial es que la inmensa mayoría de la población rural estaba compuesta por campesinos, pero los pazos y casonas de la hidalguía -junto con algunas casas rectorales de curatos ricos-, dispersos por toda Galicia, marcaban el paisaje y servían como referencia social. Precisamente por esto, sobre las residencias rurales del sector hidalgo-nobiliario hay una amplia bibliografía procedente de estudiosos de historia del arte que han hecho un notable esfuerzo por establecer su tipología arquitectónica y por conocer su patrimonio; los espacios lúdicos, como los jardines, han recibido una especial atención recientemente por parte de Jesús Angel Sánchez García, siguiendo la pauta cultural de estudios sobre jardines españoles, lo que ha aportado una nueva perspectiva ${ }^{20}$. Sin embargo, los historiadores del arte se

20 SANCHEZ GARCIA, J. A.: "El Jardín de una élite: los Bermúdez de Castro y el pazo de Montecelo en los siglos XVIII y XIX”, en FERNANDEZ CORTIZO, C.J. y otros (eds.), Universitas: homenaje a Antonio 
han preocupado poco por poner en relación los edificios con sus contenidos o con la existencia de sus habitantes, y apenas les han interesado las casonas de la hidalguía, por carecer de interés artístico. Estas cuestiones, sin embargo, han merecido la atención de historiadores modernistas -en especial P. Saavedra, A. Presedo y V. Migues $^{21}$-, si bien se mantiene la dificultad de acceder a los archivos privados.

En las dos provincias occidentales, había en 1753/1762 un total de 123.178 familias plebeyas y 2.634 familias "nobles", el 2,13\%, un poco por debajo de la media del $3,06 \%$ de Galicia. En la de Santiago eran unas 2.100 familias, solo el 1,8\% del total del vecindario, y el 4,7\% en la de Coruña, 534, cifras muy inferiores a las de la Galicia oriental -llegaban a superar un tercio del vecindario en la franja interna de Lugo-, pero el menor porcentaje se correspondía con un mayor nivel de riqueza, en general. Como veremos, los nobles e hidalgos preferían vivir en las ciudades y villas, donde a mediados del XVIII residía casi la quinta parte de las familias de este sector, y los que podían, repartían su tiempo entre las ciudades y el campo, lo que complica la definición de su modo de vida. Solo una minoría muy estrecha residía en Madrid y podía permitirse mantener casa abierta en Galicia; pero su absentismo casi permanente o su presencia ocasional y difusa, no servía para generar modelos de comportamientos.

Vivir en un pazo, todo el año o solo unos cuantos meses, era el privilegio de un conjunto de familias, tituladas o no, que constituían la minoría aristocrática de la que en sí misma significaba el grupo nobiliario y que disfrutaban por herencia de las ventajas de vivir en su seno, además de poder asumir el coste constructivo y de mantenimiento que implicaba este tipo de residencias. Se trataba de un grupo acomodado constituido sobre todo en los siglos XVI y XVII, período en el que abundan las fundaciones de mayorazgos, pero por eso mismo, el pazo que se conoce hoy en la Galicia occidental no se configuró hasta bien entrado el siglo XVII, con el triunfo del barroco, alcanzando su plenitud en el XVIII. No se trataba solo de viviendas de placer para el verano y el otoño, sino lugares para hacer presentes y visibles a las familias en aquellas zonas donde tenían sus intereses económicos, sus tierras, rentas y señoríos.

En su configuración material, los pazos eran en realidad, espacios aislados que dentro y alrededor reunían casi todo aquello que necesitaban, aunque se situaran cerca de algún núcleo urbano o semiurbano donde podían surtirse. Los distinguía su habitabilidad interior, amplia, diversificada y multifuncional, desconocida en las demás casas de su entorno, y la previsión y provisión de cuanto pudiera afectar a la vida diaria, desde lo doméstico hasta talleres con el instrumental necesario, telares, bodega, etc., y en las fincas que rodeaban a las edificaciones, una capilla -aunque solía haber oratorios privados en el interior-, estanque, palomar, huerta, incluso almazaras de aceite o batanes. Los jardines pacegos se desarrollaron más en el siglo XIX que en el XVIII, pero fueron evolucionando en su trazado desde su origen como huertas a

Eiras Roel, Santiago, Universidad, 2002, 2, pp. 113-135. Y El Jardín de los pazos: ensayo histórico, Madrid, Biblioteca Nueva, 2010.

21 SAAVEDRA FERNANDEZ, P.: "El pazo y su vida cotidiana", en Galicia renace, Santiago, Xunta de Galicia, 1997, pp. 399-425. PRESEDO GARAZO, A.: "Luxo e cultura nos pazos da fidalguía galega, 16001841", Boletín Auriense, 31 (2001) p. 143. MIGUES, V.M.: Pousas e fidalgos no Miño Medio: arquitectura, territorio e sociedade nos solares da Terra de Chantada, Lugo, Diputación, 2004. 
espacios de disfrute, con una notable riqueza botánica y una creciente intencionalidad simbólica.

Es fácil imaginar la vida de sus residentes, en especial la de sus mujeres, ya que el servicio doméstico las supliría en sus teóricas obligaciones, y la comodidad que las rodeaba estaba a años luz de la precariedad de sus vecinas. Los pazos encarnaban el modo de vida del señorío rural y el ámbito en el que a diario se movían nobles e hidalgos, pero también el ámbito rural en el que se situaban incidía en la vivienda, no solo porque en el campo había posibilidades de construcción más espaciosas y porque se podían reunir funciones económicas y sociales determinadas, sino porque adoptaban rasgos de la arquitectura popular.

A ese modelo responde, como pocos, el pazo de Ortigueira, situado en Santa Cruz de Rivadulla, localidad a unos quince kilómetros de Santiago. Gracias a las declaraciones del Catastro de La Ensenada conocemos sus caracteres externos y su contexto y gracias a un inventario de 1753 podemos reconstruir su contenido, afortunada rareza estadística que nos permite hacernos una idea casi completa del modo de vida de esta casa. En efecto, en ese año, al morir el segundo marqués de Santa Cruz de Rivadulla, don Ignacio Antonio Armada y Salgado, se realizó un inventario notarial, ya que el único hijo y heredero no había alcanzado la mayoría de edad. De la declaración catastral consta que en la enorme edificación quedaron como únicos habitantes la marquesa viuda, doña Ana Ignacia García de Castro y don Juan Ignacio Armada Mondragón (1722-1787), que estaba soltero cuando se inventariaron los bienes de su padre, aunque pronto se casaría con María Ana Caamaño Mondragón y Sotomayor. Para su servicio tenían dos litereros -en la casa había varias sillas de paseo decoradas lujosamente-, cuatro criados mayores, tres criados de menos de 18 años y cinco criadas. El palacio se situaba en medio del coto jurisdiccional del que tenían el señorío y estaba rodeado de 120.265 metros cuadrados de tierra en una sola unidad, que estaba dedicada a "monte y jardín", es decir, no tenía una dedicación agrícola, aunque una gran parte de ese terreno estaba cubierto de naranjos, huerta bien cultivada, "frutales en hilera" y un extenso olivar. Fuera de ese bloque compacto y placentero, la familia era propietaria del $13.5 \%$ de la superficie del coto, que trabajaban sus criados y caseros; por eso mismo tenía dos pares de bueyes, una vaca de leche con su cría, seis cerdos, treinta y una ovejas y carneros, y contaba con dos molinos para la molienda del grano y un molino de aceite, lo que resulta extraordinario en la Galicia occidental. El interior del palacio, reflejado en el inventario, estaba repleto de un rico mobiliario: en los dormitorios había camas de palo de rosa con colgaduras de damasco y brocatel, almohadones de raso dispuestos sobre estrados cubiertos de alfombras de China, tapicerías de materiales caros, sillas forradas de felpa y de raso, a juego con las cortinas; más de cincuenta cuadros de tema casi siempre religioso adornaban las paredes, y 512 volúmenes llenaban los anaqueles de la biblioteca. Las joyas y objetos de orfebrería son incontables: además de 1.394 onzas de plata labrada en monedas, había un broche en forma de ramilletes de flores con doce esmeraldas, topacios y un zafiro, un "barrilillo de oro que sirve de caja de tabaco guarnecido de diamantes clavados en plata", un reloj con "caxa de oro y diamantes", "un miramelindo de oro gravado con chispas de rubies y una esmeralda", "trece sortijas rodeadas de brillantes, esmeraldas, zafiros; dos collares de once hilos cada uno de perlas orientales; veneras de oro y de 
plata, relicarios adornados de granates y filigrana de oro; fuentes, copas, platos, jarras $\mathrm{y}$ fruteros de plata y una serie interminable y deslumbrante de cosas caras y raras, no producidas en Galicia, en enormes cantidades ${ }^{22}$. Como veremos, la familia mantenía por entonces un palacio en Compostela, pero se haría construir otro más ostentoso y amplio a fines del XVIII.

En la zona coruñesa, el pazo de Mariñán obedece a pautas similares, a pesar de que su propiedad no pertenecía a nobles titulados como la anterior. Su construcción se debió a don Diego José de Oca, casado en 1744 con doña Jacinta de Navia-Osorio, hija de los marqueses de Santa Cruz de Marcenado, si bien la pareja vivía en la ciudad de Betanzos parte del año. En el Catastro daban como residencia estable la casa y pazo de Oseiro, edificación de un alto que medía 25 varas por 12 varas, que ocupaban ellos y su hija menor de edad -nació en 1745-, contando para su servicio con tres doncellas, dos pajes, dos criados y cuatro criadas. En esa fuente fiscal, Mariñán aparece solo como una alquería de 12 por 38 varas, pero sin duda por su privilegiada situación, cerca del mar y de Betanzos, en los años sesenta del XVIII mereció la atención prioritaria de la familia, que encargó a maestros de obras de nombre desconocido y formación poco sofisticada según los especialistas, una reconstrucción y ampliación destinadas a certificar la nobleza de sus propietarios. Fueron estos los que impusieron un edificio en forma de ele, con patio y solaina, bodega, tullas, almacenes, reservando el piso noble como vivienda de la familia, dividida en salones -el salón del estrado era la pieza clave- y cuartos diferenciados para los señores. La hija, doña Joaquina Josefa de Oca, prosiguió las obras, de modo que el pazo fue adoptando forma de "u", con una magnífica escalinata adornada con las efigies en piedra del mayordomo y el paje, vestidos a la moda, así como numerosas figuras de indios que recordaban el antiguo pasado de la familia en la administración americana. La inversión en esta casa no impedía que ella viviese en Betanzos y sobre todo en Compostela, aunque en 1766 pasó a residir en Mariñán con su marido, el vizconde de Pegullal, por lo que el complejo se reorientó como quinta de placer, reorganizando los jardines y añadiendo en 1780 una capilla. En 1805 era propiedad de don José Joaquín de Yebra, señor de Láncara, que prefería su vivienda urbana de Santiago, ciudad en la que tenía al menos otras tres casas; disponía también de otras cuatro rurales, una de las cuales, la de Graíces, se consideraba "de familia"; un inventario de 1805 permitió a Jesús A. Sánchez exponer la enorme disponibilidad de mobiliario, ajuar y de todo lo que identifica el bienestar posible en aquella época y entorno ${ }^{23}$.

Mucho más numerosas que los pazos eran las casonas que con diferente denominación, se situaban en un plano inferior por su tamaño, sus caracteres y su estructura. En general, su tipología se adaptaba al contexto comarcal y a la sociedad rural circundante y solían ser verdaderas unidades de explotación, no sólo por el tamaño de las fincas que las rodeaban, sino por el número y espacio de las estancias que se

22 Archivo del Reino de Galicia, libro personal de legos de Santa Cruz de Rivadulla, legajo 2414 y Archivo Histórico Universitario de Santiago, Protocolos, legajo 2838, fs. 45 a 79.

23 SANCHEZ GARCIA, J.A.: Mariñán. Pazo de los sentidos, A Coruña, Diputación, 1999, pp. 37, 40, $53,59,270$. 
añadieron al lado o cerca de las viviendas ${ }^{24}$. Un tipo muy común era la edificación de gran tamaño, cuadrangular o rectangular, con corral en el interior al que se abría un corredor y que servía como patio o centro distribuidor. Era habitual que la estructura principal de la vivienda se prolongase con tramos murales alrededor de los cuales se erigían nuevas dependencias como hornos, cuadras, pajares, bodegas, capillas, etc. En el interior, durante el siglo XVIII aparecen gabinetes, salas, antesalas, y algún patín en las mejores. En niveles inferiores a ese modelo, se extendía una amplia y variada gama, que en gran medida se adaptaba a las características de la zona y a los materiales existentes en estas, por lo que apenas se diferenciaban de las pertenecientes a campesinos ricos, salvo en que solían tener algún elemento diferenciador de carácter simbólico. En todo caso, las familias de la nobleza y de la hidalguía rurales, o incluso los curas párrocos que disponían de rectorales importantes, vivían en espacios privilegiados si se compara con el campesinado, pero, sin duda influían en los modos de vida de este.

En el rural de la Galicia occidental, la extrema precariedad de medios materiales de la mayoría de las familias campesinas se constata con facilidad a través de las fuentes fiscales, las escrituras notariales y las escasas referencias de comentaristas coetáneos. Empezando por estos, son unánimes en su percepción, sumamente negativa. El sastre francés Guillaume Manier, en su visita a Santiago en 1726, decía de las casas de los campesinos que "las vacas duermen en la misma casa, con la reserva de un palo que los separa, con el pilón para comer. Los cerdos y otros animales están en libertad de andar patrullando durante la noche por todos los rincones de la casa". Pero no era mejor lo que exponía el gallego padre Benito Jerónimo Feijoo en 1739 en las páginas del Teatro crítico ya que "en estas tierras no hay más que gente hambrienta ni más desabrigada que los labradores. Cuatro trapos cubren sus carnes; o mejor, diré que por las muchas roturas que tienen las descubren. La habitación está igualmente rota que el vestido, de modo que el viento y la lluvia se entran por ella como por su casa". En 1764, el italiano Paolo Bacci, canónigo de la catedral de Arezzo, explicaba que "como de costumbre pasamos primero por la cuadra y luego por la cocina, donde había unos cerdos. La cocina y la cuadra eran una sola habitación, divididas por una pequeña pared. En la cocina estaba la cama, hecha con un poco de paja y unas mantas, pero sin sábanas, dentro de una especie de cajón hecho de madera". Y en 1765, el jurista lucense Juan Francisco de Castro, afirmaba que sus paisanos vivían "como brutos, con quasi los mismos alimentos que estos y con poca menos indecencia en sus habitaciones, atrayendo en sí el oprobio del resto de España"25.

En efecto, la mayoría de las casas era de muy pequeño tamaño y las construcciones eran muy básicas, como explican los visitantes, aunque una parte creciente de las

${ }^{24}$ MIGUES, V.M.: "Entre la casa institucional y la casa residencial: imagen social y justificación simbólica de la hidalguía en Galicia", Obradoiro de historia moderna, 14 (2005), pp. 201-220.

25 El texto de Manier puede verse en GARRIDO, G.A.: Aventureiros e curisosos. Relatos de viaxeiros extranxeiros por Galicia, séculos XV-XX, Vigo, Galaxia, 1994, p. 161. El de Feijoo procede del Teatro Crítico Universal, discurso 12, Madrid, 1739, VIII, p. 411. El de Bacci, HOYOS SANCHO, N. de: "Notas de un peregrino italiano a Santiago en 1763- 1764", Cuadernos de Estudios Gallegos, 19 (1964), p. 127. El de Juan Francisco de Castro en Discursos críticos sobre las leyes y sus intérpretes, I, Madrid, 1765, p. 200. Hay más en GARCIA-BLANCO CICERON, J: Viajeros angloparlantes por la Galicia de la segunda mitad del siglo XVIII, A Coruña, Fundación Barrié, 2006. 
casas del XVIII tenía un alto que diferenciaba su disposición interior y su disponibilidad habitable. En general estaban fabricadas con materiales de baja calidad; debemos tener en cuenta que la masa forestal maderable existente en la Galicia occidental era inferior al dos por ciento de la superficie, que las piezas de madera grandes no se conseguían fácilmente y que la expansión del pino - madera barata- era incipiente todavía a mediados del XVIII; por otra parte, el arbolado estaba sometido a control oficial ya que las maderas grandes se destinaban a la construcción naval en Ferrol. En cuanto a la piedra de construcción, tampoco resultaba de fácil obtención, tanto por su extracción y labrado, como porque los espacios donde la había tenían sus propietarios, particulares o colectivos que restringían o cobraban $\mathrm{su}_{\mathrm{uso}}{ }^{26}$.

Nada de eso refieren las fuentes, ni siquiera el Catastro, que se centra en el tamaño y los caracteres constructivos en la medida en que tenían repercusión fiscal, como ya se dijo. Sin embargo, aporta un dato que es necesario tener en cuenta: la existencia de un buen número de casas vacías, general a toda Galicia, de modo que en la provincia de Santiago lo estaba el 11,9\% y en la de Coruña el 18,4\%. Una parte eran de familias pudientes, pero muchas otras era de campesinos, que las empleaban como almacenes o bien por su ruina solo servían como refugios.

En el estudio sobre la comarca de Trasdeza realizado por H. Rodríguez Ferreiro, de $1.799,49$ estaban arruinadas $(2,7 \%)$ y 67 vacías $(3,7 \%)$. Las 1.683 edificaciones que es declaraban habitadas acogían a 1.625 grupos domésticos de entre 2,85 y 4 habitantes, lo que significa que algunos tenían más de una. Dos tercios de estas casas campesinas eran terrenas, es decir, de una sola planta, normalmente de forma rectangular. Su superficie era muy variable, desde seis metros cuadrados - eran simples casetas- a otras de cien, pero aun siendo estas últimas del mismo tamaño que muchas con una altura, siempre estaban menos valoradas fiscalmente. Era en este tipo de construcciones donde solían convivir en el interior las personas y los animales. Las de un alto tenían las cuadras en el bajo y la vivienda arriba y el espacio era mayor casi siempre: las más pequeñas eran de 24,25 metros cuadrados y las mayores de 155,43. En ambos casos, no era raro que una misma unidad familiar tuviera varias casas terrenas con funciones diferenciadas - establo, pajar-, y desde luego, tenían un corral y una era donde los animales andaban sueltos. Dado que en las aldeas, cada casa tenía esos espacios alrededor, además de una huerta o alguna tierra de cultivo, se podía ampliar su habitabilidad, de ahí que en esta comarca, el tamaño de las viviendas tuviese una clara correlación con el número de componentes del grupo doméstico; esto se advierte especialmente en las casas de un alto, que revelan una mejor posición económica y un grupo doméstico más amplio, a veces con algún criado, como sucedía en un tercio de los casos -hidalgos, párrocos o campesinos fuertes-. Esa correlación espacial favorecida por la organización exenta de las casas, era más visible en el interior lucense; allí las casas de un alto eran el $41 \%$, no en vano las familias eran más amplias ${ }^{27}$.

En el entorno compostelano, especialmente en el valle del Ulla, a través de los inventarios se observa también que la casa rural era casa-explotación, donde se mez-

26 De estos problemas nos ocupamos en REY CASTELAO, O.: A Galicia clásica e barroca, Vigo, Ed. Galaxia, 1998.

27 SOBRADO CORREA, op. cit. (nota 6), p. 496. 
claban personas y animales, cosas personales y aperos de labranza, todo en espacios pequeños, que cambiaron un tanto entre los siglos XVII y XVIII en su grado de especialización. Las casas terrenas tenían dos subtipos, la casa con construcciones auxiliares -celeiro, chope- y la casa con construcciones y cortes o cuadras en las que estaban los animales. La aparición del sobrado o semi-alto obedeció, al principio, a la necesidad de almacenar maíz, pero se fue dividiendo mediante un tabicado básico y allí se colocaron progresivamente las huchas y arcas, los lechos adosados a muros o en los vanos, sin que hubiera puertas ni un corredor. En las casas de un alto solía haber arriba dos o tres huecos, a los que se ascendía por una escalera rudimentaria; y solo había una ventana en la parte de delante, que era indistintamente habitación o comedor de las ocasiones. Los cambios van añadiendo un corral y una era diferenciados, aumentan las referencias a caballerizas y bodegas y disminuyen las de barras, celeiros o alpendres para almacenar maíz; en el siglo XVIII aparecen en las eras los canastros, hórreos y cabanas -sobre todo estas- en el 52,9\% de los casos; parecido cambio se constató en el interior de Lugo, donde los hórreos aparecen en el 18,3\% de las casas en la segunda mitad del XVII y en el $49,8 \%$ en el siglo XVIII ${ }^{28}$. En ambas zonas, los hórreos tenían otras funciones complementarias.

En cuanto a los interiores domésticos, los inventarios post-mortem corroboran la convivencia entre personas y animales, sin que hubiera divisiones ni zonas delimitadas, sino una amalgama en la que se mezclaban aperos, muebles, ajuar, menaje, etc. En la cocina el elemento primordial era el pote, que suele aparecer como componente importante de las dotes matrimoniales, junto con algunas tixolas o sartenes, y asadores; los manteles, toallas y sábanas eran pocos y de baja calidad y cuando no estaban en uso se guardaban en las arcas de madera que también se enumeran en las dotes. El mobiliario era pobre: cuando hay lechos, tienen un armazón de madera, con un jergón de paja o un colchón de lana; no son raras las cámaras o camarinas, pero lo normal eran las medias camas o camas de campo, que muchas veces son alfambres o alfamares, simples esteras con almohadas y sábanas. En realidad, llaman más la atención las ausencias que las presencias: nunca aparecen cunas, no había armarios -muy elitistasy las camas propiamente dichas o los asientos con respaldo eran un bien escaso ${ }^{29}$. En este ambiente de precariedad que caracteriza a la inmensa mayoría del campesinado, no se puede hablar de feminización del ambiente, ya que la función doméstica de las mujeres se reducía a la elaboración de la comida y a lavar ropa; la mayoría de ellas se dedicaba más a las tareas agrícolas, a la atención del ganado y a mil actividades complementarias y lo que diferenciaba a unas de otras era el medio familiar en el que se desenvolvían y en el número de personas que pudieran ayudarlas.

28 SOBRADO CORREA, op. cit. (nota 6), p. 533.

29 ROZADOS LORENZO, A.: "Marco material de la vida familiar en la Galicia del Antiguo Régimen", en BERMEJO, J.C. (ed.), Parentesco, familia y matrimonio en la historia de Galicia, Santiago, Universidad, 1989. REY CASTELAO, op. cit. (nota 14), diversas páginas. 


\section{VIVIR EN LA CIUDAD}

El marco arquitectónico en el que se desenvolvía la vida cotidiana está en Galicia bien estudiado en lo concerniente a los palacios urbanos, ya que por su valor artístico han atraído la atención de los historiadores del Arte, bien es verdad que más por su aspecto externo que en su organización interna. En este sentido, Santiago es una ciudad privilegiada, pero, dado que sus clases sociales eran tradicionales, y que los los modelos urbanos estaban muy influidos por el clero y la nobleza allí residentes, las burguesías no han dado mucho de $\mathrm{si}^{30}$. Para encontrar a estos grupos emergentes que construyeron grandes casas para dejar constancia de su éxito, es preciso atender a la ciudad de A Coruña en la segunda mitad del siglo XVIII, cuando despuntó a la par que lo hacía la actividad comercial; las novedades en la configuración del caserío han sido estudiadas por los historiadores del Arte, en especial Alfredo Vigo y Jesús A. Sánchez García, cuyas publicaciones sobre las casas creadas para ricos comerciantes, aportan una perspectiva muy aproximada de quienes vivían en espacios concebidos con un concepto nuevo, entre lo utilitario y lo representativo ${ }^{31}$. En ese contexto arquitectónico es donde se han podido enmarcar los estudios de los contenidos de las casas publicados antes por B. Barreiro y A. Rozados sobre Compostela y los de E. Sampayo sobre A Coruña, realizados sobre inventarios post-mortem ${ }^{32}$.

La ciudad de Santiago es la mejor conocida no solo por el temprano inicio de los estudios desde la Universidad - como ya hemos dicho- y por la disponibilidad documental de sus archivos, sino sobre todo por ser la ciudad más poblada de Galicia hasta fines del XVIII y por su carácter de referencia religiosa y cultural -que no administrativa- con una importante influencia en el resto del Reino. En el Catastro constan 374 vecinos nobles e hidalgos, pero un grupo de alto rango -los condes de Altamira y Amarante, los marqueses de Montesacro y de Parga, entre otros-, no vivían en sus casas compostelanas, sino en Madrid, y otro grupo más numeroso de caballeros y títulos, cuya base económica se situaba en el campo, tenían su residencia rurales para pasar parte del año por placer y para recaudar las rentas de su patrimonio. El profesor Eiras detectó en las fuentes notariales que al menos doce de las 155 familias de la elite tenían esas casas rurales ${ }^{33}$, pero seguramente eran más; en este grupo destacaban el ya mencionado marqués de Santa Cruz, que dejó su palacio antiguo para pasarse a

30 ROSENDE VALDES, A.: Una historia urbana. Compostela (1595-1780), Gijón-Vigo, Nigratrea, 2004.

31 VIGO TRASANCOS, A.: A Coruña y el Siglo de las Luces: la construcción de una "Ciudad de comercio" (1700-1808), Santiago, Universidad, 2007; “A Coruña y el Reino de Galicia: imágenes urbanas de un centro de poder (1501-1800)", A Coruña 1208-2008: La construcción de una ciudad, A Coruña, Concello, 2008. pp. 243-290; "Las “casas de Paredes": un ejemplo de decoro urbano dieciochesco en el puerto de La Coruña”, Cuadernos de estudios gallegos, 36, 101 (1986), pp. 209-223. SANCHEZ GARCIA, J.A.: "Comerciantes y arquitectura en La Coruña dieciochesca, el proceso constructivo de las "Casas de Paredes", Semata, 12 (2001), pp. 177-239.

32 BARREIRO MALLON, op. cit. (nota 13), ROZADOS, A.:"Santiago de Compostela y su entorno, el cuidado de la imagen y del medio doméstico en los siglos XVII, XVIII y XIX”, 42, Compostellanum (1997), pp. 477-490. SAMPAIO SEOANE, E.: "Un estudio sobre el entorno urbano de La Coruña del siglo XVIII: el ámbito cotidiano", Obradoiro de Historia Moderna (1997), p. 263. No son los únicos sobre la Galicia occidental: GARCIA GARCIA, M.: "Condiciones de vida material de los vigueses según los inventarios postmortem en los siglos XVII y XVIII”, Boletín del Instituto de Estudios Vigueses, 2 (1996) pp. 107-118.

33 EIRAS ROEL, A.: Santiago de Compostela, 1752, Madrid, Tabapress, 1990. 
otro sumamente suntuoso en 1803, los condes de Ximonde y de Priegue, que hicieron lo propio a fines del XVIII, el marqués de Bendaña, el señor de Láncara, la ascendente familia Porras, etc. ${ }^{34}$ Quienes no tenían esas casas en el campo, solo podían aspirar a disfrutar de las ajenas; en la asidua correspondencia entre del jesuita padre Isla y su hermana, María Francisca, residente en Compostela, se mencionan con frecuencia sus visitas veraniegas de uno o varios días a amigos que tenían sus casonas o pazos en aldeas próximas a la ciudad o situadas en la costa, quizá el único asueto extra-domiciliario que este tipo de familias de la pequeña hidalguía se podía permitir. A mediados del XVIII la vida tenía que ser bastante cómoda para aquellas 155 familias -el 3,4\% del vecindario-, que tenían un tamaño similar a las demás -3.8 componentes-, pero disponían de un amplio servicio doméstico -3.4 criados-, o para las de la burguesía administrativa y mercantil, que para el mismo tamaño familiar disponían de 1.5 criados. Vivían en casas de dos altos, recargadas y ostentosas, con muebles variados de maderas preciosas, como el palo de rosa de las camas, colchas de seda, arrobas de plata labrada en platos, bandejas, aguamaniles, profusión de cuadros y láminas de tema bíblico, rosarios, crucifijos, etc. ${ }^{35} \mathrm{Su}$ estilo de vida estaba muy por encima de las 585 familias de las clases medias (el 12,9\%), residentes en casas que muchas veces tenían tienda en el bajo y un alto para vivir; del artesanado -1.798 vecinos, el 39,9\%-, de la amalgama de otras 1.694 de dedicaciones muy variadas $(37,6 \%)$ y de los 274 campesinos urbanos $(6,2 \%)$, que vivían en casas terrenas arrendadas, por lo general.

En Compostela hubo cambios en la segunda mitad del XVIII, pero fue en A Coruña donde se desplegó un modelo urbano diferente, marcado por la configuración de un referente "cortesano" merced a la construcción de los nuevos palacios de los representantes de la Corona y por la nueva burguesía mercantil enriquecida con el comercio americano, abierto en 1764/67. En lo primero, es preciso decir que en Galicia no hubo un espacio cortesano que sirviera de modelo a los grupos acomodados hasta que se construyó en A Coruña el palacio del Gobernador Capitán General ${ }^{36}$. Atendiendo a la jerarquía civil, era la máxima autoridad del Reino de Galicia, pero casi todos los que ocuparon ese cargo eran foráneos y no todos estaban casados al ser nombrados, ni los que sí lo estaban residieron en Galicia con sus familias, ya que sus mandatos fueron breves hasta el XVIII. Sí lo hicieron los que estuvieron por un tiempo largo, como por ejemplo, el conde de Itre, que estuvo en A Coruña desde 1738 a 1756; en 1753 , cuando contaba con 66 años, tenía en su compañía a su mujer, y para el servicio de ambos disponían de dos pajes, un mayordomo, dos litereros, un lacayo, un cocinero y tres criadas, que el salario del conde, 120.000 reales anuales, podía cubrir con holgura. Sin embargo, vivían en las llamadas "casas reales", bastante deterioradas y sin el carácter "regio" que correspondía al representante del rey. Para resolver esta carencia, en 1747 se proyectó la construcción de un palacio que fue ocupado por el Gobernador marqués de Croix en 1758, pudiendo hablarse entonces de un lugar acor-

34 Sobre estos palacios, ROSENDE VALDÉS, op. cit. (nota 30), p. 92.

35 BARREIRO MALLON, op. cit. (nota 13), ROZADOS, op. cit. (nota 32), p. 477.

36 Secundariamente, el del comandante general del departamento marítimo, residente en Ferrol: VIGO TRASANCOS, A.: "La "Casa del Rey" en la que vive el comandante general del departamento marítimo de Ferrol. Símbolo de poder y nudo urbano de la nueva ciudad dieciochesca (1751-1768)", Minius, 19 (2011), pp. 155-177. 
de con la representación y el lustre de tan alta magistratura y adecuado para organizar una pequeña corte; el palacio, que luego fue muy imitado, tiene un carácter hermético y unitario, destacando un amplio patio interior que organizaba los diferentes espacios. En la ciudad residía también en 1753 el Intendente-Corregidor, don José Avilés Iturbide, de sesenta años, en compañía de su esposa y de dos hijos, que contaba con capellán propio, un paje, una doncella, un cochero, un lacayo y dos criadas, gracias a su sueldo de 76.000 reales. El intendente vivía en la casa de la Veeduría, propiedad de la Corona, que fue reformado en 1758, ampliando el espacio habitable, de modo que la familia viviría en la planta noble, mientras las habitaciones de los criados, la cochera y las caballerizas se situarían en la planta. El resultado fue un conjunto cortesano de gran empaque y adaptado a las tendencias de la segunda mitad del siglo XVIII ${ }^{37}$.

La presencia de la Real Audiencia de Galicia, de la Intendencia y de instituciones del ejército y de la marina, hacía de A Coruña el lugar de residencia de numerosos y bien pagados cargos civiles y militares que ocupaban un lugar privilegiado en sociedad urbana, pero su influencia en los modos de vida estuvo en parte limitada por la temporalidad de sus responsabilidades y por la condición foránea de la mayoría. De los que residían allí en 1753 destacaba el gallego don Bernardino Antonio Freire de Moscoso, Intendente General de Marina, de 62 años, que vivía con su mujer y sus dos hijos, un capellán, cuatro pajes, siete criados (literero, cocinero, cochero, un negro esclavo), dos doncellas y cuatro criadas. El joven contador principal del ejército, don Francisco Mendoza, con 31 años y 30.000 reales anuales, vivía con dos hermanas y dos sobrinas, y tenía dos criados y tres criadas. También el regente de la Audiencia, don José Manuel de Villena, de 40 años, casado, cuyo sueldo de 30.000 reales le permitía tener mayordomo, un paje, dos silleteros, un lacayo y cuatro criadas. Los demás componentes de la Audiencia tenían sueldos menores pero también disfrutaban de criados y de un buen modo de vida ${ }^{38}$.

Como mansión señorial, destacó en la ciudad la del polígrafo ilustrado don José de Cornide (1734-1803), que residió en ella hasta su marcha a Madrid. Había sido construida por su padre,oidor de la Real Audiencia y hombre público de gran prestigio social por su matrimonio con una hidalga, cuyo afán de notoriedad se advierte en una vivienda con aire francés -el exterior es mucho más interesante y cuidado que el interior-, quizá por ser obra de uno de los arquitectos franceses del arsenal de Ferrol; la familia tenía su residencia rural en el pazo y torre de Mondego, donde celebraban frecuentes fiestas. En una calle céntrica, el hidalgo y comerciante don José Ramos, que residía en Cádiz y tenía intereses en América, en 1780 mandó construir un edificio enorme destinado a subrayar su éxito personal en los negocios, pero nunca llegó a ocuparlo, de modo que acabó siendo sede del Consulado de Comercio en 1785. Se concibió con un patio interior de inspiración gaditana, lo que también se nota en la enorme terraza y en la torre-mirador; las baldosas de Génova, el ladrillo sevillano y los azulejos de Talavera, rematan este conjunto tan poco galaico ${ }^{39}$. La casa urbana de don Antonio Vicente Zuazo Mondragón, que desde 1798 se hizo con el título de

37 VIGO TRASANCOS, op. cit. (nota 31), pp. 108, 128.

38 BARREIRO MALLON, B.: La Coruña a mediados del siglo XVIII, Madrid, Tabapress, 1990.

39 VIGO TRASANCOS, op. cit. (nota 31), pp. 173, 219 y 225. 
marqués de Almeiras, se inició en 1715 por mandato de don Antonio Zuazo; al inventariarse en 1771 se revela como un verdadero modelo de la riqueza urbana, con espacios y objetos individualizados. Podrían citarse otros casos de comerciantes, hombres de negocios e hidalgos enriquecidos que en la segunda mitad del XVIII modificaron el caserío urbano coruñés. En todos debe tenerse en cuenta la importante influencia que procedía de Ferrol, ya que en muchos casos fueron arquitectos e ingenieros de ese arsenal quienes diseñaron las casas.

En cuanto a los interiores coruñeses, los inventarios localizados por E. Sampayo ${ }^{40}$, unos cien de 1680 a 1820, permiten constatar que hasta mediados del XVIII no había diferencias sociales claras en los bienes muebles y que solo una minoría tenía algunos rasgos de lujo, dentro de una general preferencia por lo funcional y duradero. Pero a partir de los años sesenta, en las casas de los sectores más acomodados, empiezan a aparecer algunos armarios y estanterías, los asientos cómodos se hacen más numerosos, y asoman las piezas de madera lacada y los muebles pintados a juego. El cambio y el mayor refinamiento se detectan también en los utensilios de cocina, de metal todos -cacerolas, cazos, sartenes, potes- y una cierta individualización de las costumbres se detecta en el servicio de mesa -salseras, soperas, mostaceras, etc.-, cada vez de mejor calidad, de modo que los objetos de barro de Buño o de Asturias se quedarán para las clases humildes; la cerámica de Talavera se hizo general en la segunda mitad del XVIII, pero las familias adineradas se decantan por el peltre, el estaño, incluso plata, cada vez más frecuentes, y algunas veces se enumeran en los inventarios, vajillas inglesas o francesas. En la vestimenta, es perceptible una clara mejora de los materiales, ya que se pasa de la estopa y la estopilla al terciopelo, la seda, el damasco y el algodón. En lo ornamental hay referencias a objetos decorativos en el 77,3\% de los inventarios de esos sectores, pero apenas se localizaron libros -constan solo en una docena de inventarios, cuando en Santiago los había en el treinta por ciento ${ }^{41}$-. A fines de siglo, menudean el mobiliario y los ornatos sin utilidad práctica -mesas de noche, papeleras, tapizados, etc., lo que revela la consolidación del cambio en el modo de vida coruñés. El aumento del número de muebles acompaña a los cambios urbanísticos de la segunda mitad del XVIII, en especial a la ampliación de los espacios y su creciente división y especialización. Pero también aumentan las diferencias entre los grupos ricos y los humildes: baste decir que el número medio de arcas, bancos, catres, mesas, sillas y taburetes pasa de 46,3 a 52,7 en 1751-1820 entre los grupos comerciantes; de 28,5 a 47,6 entre los profesionales liberales y solo de 16,4 a 16,9 entre los más modestos, un indicador simple pero claro de la desigualdad de las mejoras.

\section{CÓMO LLEGABAN LAS COSAS A LAS CASAS}

Como es lógico, en la Galicia occidental, el principal acopio de bienes procedía de la herencia y los contenidos de las casas pasaban de generación en generación. Dado

\footnotetext{
40 SAMPAYO SEOANE, op. cit. (nota 32), p. 263.

41 ALONSO ALVAREZ, L.: "Economía e ideoloxía na Galicia ilustrada: as lecturas dos empresarios coruñeses (1700-1820)", en VENCES, S. (ed.), Liber: de libros y liberdades, A Coruña, Universidad, 1999, pp. 101-110. El dato de Santiago es de BARREIRO MALLON, op. cit. (nota 13), p. 449.
} 
que entre las clases populares, una buena parte de las bodas se hacía después de la muerte de los progenitores de él o de ella, no es extraño el deterioro por el uso de muchos de los objetos que los escribanos especifican en las escrituras de dote, y más aun en los inventarios y partijas; a través de mejoras, donaciones y legados podían transferirse también algunos bienes, si bien es verdad que no solían incluir ajuar o ropas sino cosas más sustanciales. Además, es importante subrayar que en la zona que nos ocupa, era frecuente mejorar a los hijos o hijas con quienes se convivía, con frecuencia en estas más que en ellos; también la convivencia determinaba las donaciones, que en un $38.3 \%$ eran otorgadas por solteros o solteras de edad avanzada que se procuraban el cuidado de sobrinos o sobrinas -en el $23.6 \%$ de las escrituras, el parentesco dominante era ese ${ }^{42}$. Así pues, una pareja recién constituida a partir de otra y de la convivencia, o que había recibido parte o toda la herencia de familiares sin hijos, no tendría que hacerse con cosas nuevas y esto minimizaba la importancia de la dotes. Más aún, en amplias zonas como el valle del Ulla, durante el XVIII el matrimonio a trueque fue una fórmula extendida precisamente para evitar la transferencia de bienes mediante dote ${ }^{43}$. Esto y el empobrecimiento del campesinado en la segunda parte del siglo explican el comportamiento antes descrito de las dotes, que, como en toda Galicia, se hacían a cuenta de las legítimas paterna y materna, y debían llevarse a montón para hacer la partición al morir los petrucios. En la medida de sus posibilidades los padres ayudaban a sus hijas a formar un capital dotal que era importante para crear y cimentar el patrimonio de una nueva unidad familiar. Bienes raíces, ganado, ajuar y vestido, formaban parte usualmente de las dotes campesinas, a lo que en la costa se unía algún quiñón de pesca, una conexión con los medios de producción que refrenda el espíritu utilitario y el pragmatismo de su composición ${ }^{44}$.

Pero en la práctica, a las hijas se les daba lo que se podía y, como ya dijimos, las investigaciones sobre la Galicia occidental coinciden en que no solo las dotes disminuyeron en número entre el siglo XVII y el XVIII -sustituidas por simples seguros de legítima- sino que hubo una paulatina devaluación de su composición, lo que se agravó en la segunda mitad setecientos. Esta práctica se aplicó a medida que la situación económica impidió a los padres dar a sus hijas una dote suficiente. Así pues, las dotes que se hacían no se escrituraban y las que se escrituraban eran cada vez más pobres. De los casos que se conocen, a mediados del XVII un 26,8\% superaban los 900 reales, pero solo el $11,9 \%$ a mediados del XVIII; las situadas entre 600 y 900 descendieron del $35,2 \%$ al $15,9 \%$ y si en $1640-49$ un $37,9 \%$ eran inferiores a 600 , un siglo después este nivel más humilde reunía al $72,2 \%$ de las dotes. La pérdida de importancia se ve mejor todavía en la composición por bloques, si bien los cálculos de Serrana Rial y de Concepción Burgo difieren en la contabilización de la plata y del

\footnotetext{
42 DUBERT, op. cit. (nota 12), pp. 32, 187 y 263.

43 REY CASTELAO, O.: "Mecanismos reguladores de la nupcialidad en la Galicia atlántica, el matrimonio a trueque", Obradoiro de Historia Moderna, 1, (1990), pp. 247-268.

44 RIAL GARCIA, S.: Las Mujeres de las comunidades maritimas de Galicia durante la época moderna: una biografía colectiva, Alcalá de Henares, Ayuntamiento, 2005.
} 
dinero, separados en este caso y sumados en la primera:

\begin{tabular}{|l|r|r|r|r|r|r|r|}
\hline $\begin{array}{l}\text { Tabla 1 } \\
\text { Composición de las dotes en \% }\end{array}$ & $1640-49$ & $1708-09$ & $1752-53$ & $1750-59$ & 1796 & XVII & XVIII \\
\hline Ajuar & 95,2 & 86 & 70 & 84,3 & 55 & 58,3 & 69,5 \\
\hline Ganado & 92,8 & 61 & 44 & 46,8 & 29 & 61,5 & 39,1 \\
\hline Grano & 45,2 & 23 & 28 & 19,4 & 35 & 37,5 & 43,4 \\
\hline Rentas & 42,8 & 25 & 16 & 15,2 & 12 & 25,0 & 8,6 \\
\hline Dinero & 12,6 & 34 & 41 & 23 & 27 & 12,5 & 39,1 \\
\hline Bienes raíces & 76 & 67 & 54 & 60,3 & 53 & 33,3 & 39,1 \\
\hline Plata & 40 & & & 44,3 & & 25,0 & 26,0 \\
\hline
\end{tabular}

En Deza, un estudio basado en 180 escrituras, revela un comportamiento similar aunque con un ritmo un poco más lento, pero en cualquier caso, En 1820 están todas en dinero y el $60 \%$ lleva vestidos personales pero solo una quinta parte llevaba ropa de cama ${ }^{45}$ :

\begin{tabular}{|l|c|c|c|c|}
\hline $\begin{array}{l}\text { Tabla 2 } \\
\text { Composición de las dotes en \% }\end{array}$ & $1600-49$ & $1650-99$ & $1700-49$ & $1750-99$ \\
\hline Vestidos & 71,4 & 67,3 & 68,4 & 65,7 \\
\hline Ropa cama & 85,7 & 87,3 & 63,2 & 62,9 \\
\hline Vacas & 80,9 & 81,8 & 52,6 & 20,0 \\
\hline Ovejas & 76,1 & 87,3 & 52,6 & 37,1 \\
\hline Rentas & 28,6 & 50,9 & 36,8 & 25,7 \\
\hline Dinero & 28,6 & 29,1 & 47,4 & 74,5 \\
\hline Plata & 28,6 & 45,5 & 21,0 & 20,0 \\
\hline Huchas & 76,2 & 74,5 & 52,6 & 25,7 \\
\hline Arcas & 61,9 & 14,5 & 14,5 & 8,6 \\
\hline Calderas & 47,6 & 54,6 & 15,8 & 5,7 \\
\hline
\end{tabular}

En general, las mujeres recibían en dote, además de arcas y huchas para almacenar, y el ajuar de la casa, los medios para fundar una explotación campesina, ganado y aperos de labranza, y en ocasiones un telar y sólo a veces algún objeto de plata de escaso valor. Pero la coyuntura del XVIII provocó una creciente incapacidad económica de los campesinos para entregar bienes a sus hijas.

¿Y en la ciudad? Tomando Compostela como referencia, obviamente, también los bienes muebles se heredaban y una parte llegaba a las casas mediante las dotes. El monto y la configuración de las dotes urbanas dependían de los estratos sociales que las otorgaban, como en el campo, pero lo que se daba en cada ámbito no era lo mismo y en esa ciudad solo el 6\% se formalizaba ante notario. En torno a la mitad de los contratos dotales en Santiago corresponden al artesanado y a asalariados urbanos, el $19 \%$ a labradores rururbanos, uno de cada cinco a la elite, y el resto a progenitores con cierto acomodo -profesiones liberales, comerciantes-. Por otra parte, en el medio

45 GOMEZ BUJAN, C.: "La dote matrimonial: economía y sociedad en Deza durante los siglos XVI a XVIII", Descubrindo Deza, 3 (2001), pp. 11-51. 
urbano las dotes dobles -a los dos novios- eran escasas y muchas novias aportaban la dote y su capital dotal con su trabajo personal.

En la cúspide social, uno de los objetivos fundamentales de las estrategias nupciales era evitar la fragmentación patrimonial, y por eso se ofrecían abultadas cantidades de dinero cuya cuantía obligaba no pocas veces a pactar su entrega en varios plazos -en contrapartida, las novias, como norma, renunciaban a sus legítimas-. El desembolso que suponían iba en proporción a la importancia de cada enlace matrimonial para crear o fortalecer relaciones sociales y económicas, para proclamar el prestigio familiar, y para buscar una salida digna a la descendencia femenina, por eso casi sin excepción se hacían ante notario. Pero la monetarización se generaliza en la segunda mitad del XVIII y esto les resta utilidad para observar los objetos que las novias aportaban; la excepción la constituyen las joyas, que las llevaban casi todas las novias. En las clases medias urbanas -mercaderes, profesionales liberales y oficiales, las dotes de las novias suelen incluir dinero, entre seis mil y siete mil reales, ajuar, y algunos objetos de plata y oro. Más de la mitad de los integrantes se casaban en su propio medio profesional, al tiempo que son frecuentes las uniones entre familias de mercaderes y escribanos. A partir de 1760 la burguesía se dinamiza y los enlaces matrimoniales desempeñaron un rol fundamental en el origen de muchos de los proyectos comerciales de este nuevo período, gracias al dinero de ellas. Pero no podemos ir más allá.

Durante el siglo XVIII el artesanado constituye un grupo mediocre desde el punto de vista de sus ingresos, pero no homogéneo ya que es posible distinguir en él unas capas superiores que se aproximaban a las clases medias -plateros, escultores- y unas capas inferiores -herreros, tejedores, carpinteros, etc.- próximas a los desposeídos. La endogamia profesional no es total entre los trabajadores manuales ya que también eran numerosos quienes buscaban cónyuges en el ámbito rural cercano, o entre gentes de oficios más o menos próximos, como se observa en los matrimonios de los artesanos con criadas que habían reunido una dote con el producto de sus soldadas: una de cada tres escrituras de dote alude a que las jóvenes trabajaban en el servicio doméstico. El porcentaje de mujeres que declara auto-dotarse aumentó a lo largo del siglo XVIII, aproximándose al $40 \%$ al final de la centuria. Es posible que el deterioro de las condiciones de vida de las clases populares obligase a las jóvenes casaderas a recurrir cada vez en mayor medida al trabajo remunerado como forma de ahorro. En las dotes que entregan a sus futuros esposos, el ajuar y el dinero eran los dos elementos más frecuentes. El dinero oscilaba entre los 2.300-2.500 reales y los objetos eran poco numerosos y austeros, pero reunían lo indispensable para el hogar de una familia trabajadora: muebles de maderas de baja calidad -una mesa o bufete, un banco, algunos taburetes, una o varias arcas y tarimas para hacer de camas, que no suelen pasar de un jergón-; ropa personal, de cama y de mesa; útiles de cocina; alguna materia prima. Lo más superfluo solían ser unas almendrillas de plata o un collar de coral. Entre los sectores humildes, la evidencia es que con frecuencia el capital dotal femenino no sólo era lo único con lo que el matrimonio contaba al constituirse sino que, además, en ocasiones la dote no se acrecentaba y era la única fuente de recursos de la familia. En la segunda mitad del XVIII, la caída del salario real acrecentó las diferencias con respecto a los grupos elevados. 


\section{UN MERCADO ESTRECHO Y POCO VARIADO}

En el campo, sin duda la producción propia era dominante, lo que reducía al mínimo las necesidades de comprar cosas. Los artesanos producían para las casas lo que en estas no se podía hacer. El Catastro de La Ensenada ha permitido contabilizarlos por miles: 4.261 carpinteros, 4.021 tejedores y 5.794 tejedoras, 1.228 palilleras, 4.862 sastres y 1.406 costureras, 3.652 zapateros y 1.836 curtidores, 1.234 alfareros, entre otros. En el territorio del que nos ocupamos, había una especial concentración derivada de la densidad de población y de la necesidad de desarrollar actividades complementarias de la agricultura; en cada feligresía, entre un $10 \%$ y un $25 \%$ de los cabezas de familia tenían alguna de esas actividades, ejercidas en parte por mujeres.

La producción de autoconsumo era esencial en Galicia. En la vida diaria de miles de las mujeres de la Galicia occidental, hilar formaba parte de las tareas fundamentales, ya fuera para hacer telas de consumo casero, ya fuera para venderlas. Ellas hilaban para preparar el ajuar y vestir a sus familias, hacían y arreglaban la ropa y en muchas zonas tejían, aunque esta tarea solía estar en manos de varones. En teoría, cuanto más pequeña era la explotación agraria y más bajos los ingresos que generaba, más componentes de la familia recurrían a actividades artesanales, por eso menudeaban entre los pequeños campesinos de este territorio donde se compaginaban agricultura de subsistencias y producción de artículos para distintos mercados y, así, maximizar el rendimiento de la familia. La participación de las mujeres dependía de la división del trabajo y de la cooperación de la familia y también de la complejidad del artículo a realizar, ya que, por ejemplo, era precisa la tarea de cuatro a diez hilanderas para cubrir la actividad de un tejedor; colocar el producto en el mercado o en manos de los mercaderes implicaba viajes de los hombres y la sincronización de las tareas agrícolas.

El sector del lino tuvo su gran expansión desde mediados del XVIII. Esposas e hijas de labradores, o solteras y viudas cabezas de casa, cultivaban lino y lo preparaban o trabajaban lino importado del Báltico. No se necesitaba una formación especial y el instrumental era barato, se hacía en horas desocupadas o durante las tareas que permitían manejar huso y rueca -cocinar, cuidar ganado-, o cuando no podían hacer otra cosa -ancianas-; y lo hacían todo el año para mantener activo el telar durante tres o cuatro meses, algo de lo que solían ocupares los hombres. Una vez cubierto el consumo doméstico, los productos de lino se vendían en las ferias o a los traficantes. A ese modelo respondía el Valle del Ulla: en varias de sus parroquias, las familias con dedicaciones complementarias superaban el 30\% -61\% en Illobre, del 36 al 38\% en Vedra, Sales y otras- sin descender del $10 \%$ e las demás. Eran familias de mayor tamaño que las de labradores puros -solo el 38,5\% tenían menos de cuatro componentes pero entre los labradores eran el $62,9 \%$. Los inventarios nos han permitido ver la evolución del instrumental de hilado y de tejido existente en las casas ${ }^{46}$.

\footnotetext{
46 Estos datos en REY CASTELAO, O.: "La emigración a América en la cuenca media del Ulla: un ejemplo de análisis comarcal”, Revista Galega do Quinto Centenario, 4 (1990), pp. 177-224.
} 


\begin{tabular}{|l|c|c|c|c|c|}
\hline $\begin{array}{l}\text { Tabla 3: } \\
\text { \% en inventarios }\end{array}$ & Linaza & $\begin{array}{c}\text { Solo } \\
\text { lino }\end{array}$ & $\begin{array}{c}\text { Lino }+ \\
\text { instrumental }\end{array}$ & $\begin{array}{c}\text { Solo } \\
\text { instrumental }\end{array}$ & Telares \\
\hline $1740-49$ & 52,9 & 35,0 & 52,9 & 11,7 & 23,5 \\
\hline $1750-59$ & 62,0 & 34,5 & 58,6 & 3,4 & 20,6 \\
\hline $1760-69$ & 42,5 & 12,5 & 60,0 & 15,0 & 27,5 \\
\hline $1770-79$ & 31,7 & 19,5 & 52,5 & 12,2 & 31,7 \\
\hline $1780-89$ & 22,2 & 27,8 & 25,0 & 8,3 & 11,1 \\
\hline $1790-99$ & 26,7 & 16,6 & 23,3 & 10,0 & 6,7 \\
\hline $1800-29$ & 17,4 & 32,6 & 12,5 & 17,4 & 15,2 \\
\hline
\end{tabular}

En cuanto al comercio, los 769 comerciantes-merceros que se recontaron eran itinerantes en muchos $\operatorname{casos}^{47}$. Una parte importante de los productos se negociaban en las ferias. Debe tenerse en cuenta que en la segunda mitad del siglo XVIII se han contabilizado en Galicia 5.647 ferias y mercados, de los que 1.939 correspondían a la provincia de Santiago que nos ocupa. Aunque se negociaba sobre todo productos ganaderos y agrícolas, la venta de textiles se ha comprobado en muchas y es de suponer que se intercambiarían muchos otros productos ${ }^{48}$.

Quienes pudieran ir a las ciudades y los habitantes de estas, tenían una mejor oferta, aunque bastante limitada, de ahí que las clases superiores se surtieran de fuera, a través de los arrieros. En Santiago eran numerosos los plateros y joyeros -había 13 en 1753-, los comerciantes de lienzos y de paños -13 también-; había un fabricante de cucharas, 24 mercaderes de vidrios y Talavera y varias mujeres tratantes de objetos de barro; 112 merceros/as, latoneros y estañeros, etc. En total 564 artesanos del textil, cifra considerable para una ciudad de su tamaño; 196 zapateros, 45 cordoneros, etc. En realidad, casi el $40 \%$ del vecindario se componía de artesanos y esto hacía que la disponibilidad del mercado fuese amplia. Pero las clases superiores tenían información y conexiones con Madrid, Valladolid, Granada y Sevilla, de donde procedía gran parte de lo que no había en Galicia, y les llegaba por intermediación de arrieros maragatos, más que de mercaderes de Compostela.

Eso no cambió gran cosa en la segunda mitad del XVIII, pero sí lo hizo en A Coruña. El tráfico con América implicó mayores posibilidades de conseguir productos foráneos, no tanto americanos -aunque ya vimos que sí- como de los que llegaban a través de los comerciantes e industriales foráneos asentados en la ciudad para aprovecharse de la exportación ultramarina. También fue importante la influencia de las novedades que generaba Ferrol a través de los nuevos grupos militares y civiles que temporal o permanentemente se ubicaron allí, en especial en lo concerniente a los modelos arquitectónicos. Y finalmente, la apertura del camino del Norte que ponía en relación Madrid con Ferrol y con A Coruña, facilitó una mayor facilidad en la llegada de las novedades cortesanas y de los objetos pesados que desde entonces pudieron ser

47 CARMONA BADIA, X.: "Merceros de Castilla: estacionalidad agrícola y desplazamientos estacionales en la España Cantábrica", en GARCIA MERINO, L. y otros (comp.), Los espacios rurales cantábricos y su evolución, Santander, Universidad de Cantabria, 1990, pp. 32-43.

48 SAAVEDRA FERNANDEZ, P.: "La consolidación de las ferias como fiestas profanas en la Galicia de los ss. XVIII y XIX”, en NUÑEZ, M. (ed.), El rostro y el discurso de la fiesta, Santiago, Universidad, 1994, p. 279. 
transportados en carretas. A Coruña simboliza por lo tanto, un nuevo tipo de gusto, de tono aburguesado, pero también simboliza el aumento de las diferencias con respecto a las clases populares rurales y urbanas de la Galicia occidental, resignadas a los efectos de la prolongada fase de empobrecimiento que el profesor Eiras Roel estudió en su día a través de indicadores como los precios y los salarios ${ }^{49}$.

49 EIRAS ROEL, A.: Estudios sobre agricultura y población en la España moderna, Santiago de Compostela, Tórculo Edicións, 1990, en varios de sus capítulos. 